\title{
SEJARAH MEBEL UKIR JEPARA
}

\author{
Oktavianus Marti Nangoy; Yunida Sofiana
}

Design Interior Department, School of Design, BINUS University

Jln. K. H. Syahdan No. 9, Palmerah, Jakarta Barat 11480

ovinangoy@yahoo.co.id; yunida_ys@yahoo.com

\begin{abstract}
Since 19th century, Jepara has been wellknown for furniture and craftings. It is shown by the appcreciation from some people claiming Jepara as an intregrated region for furniture and craftings. In Jepara, making furniture and craftings activities have become ingrained part of culture, arts, economic, social and politic. It is difficult to seperate them from its history, as it is not clear the time and place of making furniture and craftings. Thus, tracking the history is necessary to do, to know the development of Jepara as an integrated region for furniture and craftings nowadays.
\end{abstract}

Keywords: furniture, craftings, furniture history

\begin{abstract}
ABSTRAK
Sejak abad ke-19 daerah Jepara telah dikenal luas sebagai daerah yang memproduksi mebel dan ukiran yang terkemuka di Indonesia, terbukti dengan adanya apresiasi dari beberapa kalangan yang menyatakan Jepara sebagai kawasan terpadu untuk mebel dan ukiran. Di Jepara, kegiatan pembuatan mebel dan ukiran telah menjadi bagian dari budaya, seni, ekonomi, sosial dan politik yang sudah mendarah daging, sehingga sukar dipisahkan dari sejarah awalnya. Tidak diketahui secara jelas, waktu dan asal usul dari pembuatan mebel dan ukiran tersebut. Untuk itu, penelusuran sejarah perlu dilakukan untuk mengetahui perkembangan Jepara sebagai kawasan terpadu mebel dan ukiran saat ini.
\end{abstract}

Kata kunci: mebel, ukiran, sejarah mebel 


\section{PENDAHULUAN}

Aktivitas pembuatan mebel dan ukiran di Jepara sudah dikenal luas terutama di Indonesia. Perannya sebagai daerah yang memproduksi mebel dan ukir sangat besar karena daerah ini mampu memproduksi mebel dalam skala yang sangat besar. Membuat mebel dan mengukir telah menjadi aktivitas harian dan merupakan penggerak perekonomian bagi penduduk daerah ini. Hal ini dapat dilihat dari banyaknya jumlah industri mebel, kios, dan bengkel yang bertebaran dari sepanjang pintu gerbang menuju kabupaten Jepara hingga ke tengah-tengah kota.

Budaya mebel dan ukir ini cukup menarik untuk diteliti karena begitu kuatnya profesi ini merasuki masyarakat Jepara seperti jamur yang terus tumbuh dan berkembang. Mebel dan ukir Jepara memiliki sejarah yang cukup panjang. Kemampuan bertukang atau mengukir diturunkan secara turun temurun dari generasi ke generasi dan kebiasaan itu terus diasah dan berkembang seiring perkembangan zaman. Dari yang dulu hanya bersifat otodidak, sekarang seiring peningkatan jumlah peminat dari dalam dan luar daerah terhadap tenaga terampil telah berdiri sekolah-sekolah dan lembaga pendidikan teknik mebel, ukir, dan desain.

\section{METODE PENELITIAN}

Metode yang dipakai dalam tulisan ini adalah metodologi deskriptif kualitatif dengan teknik pengumpulan data yang lebih ditekankan pada observasi lapangan (survei) ke beberapa industri furnitur, pengerajin ukir dan mebel serta beberapa narasumber. Guna melengkapi data tersebut, dilakukan pula observasi dari beberapa literatur review dari buku, media cetak, maupun internet.

\section{HASIL DAN PEMBAHASAN}

Secara geografis, Kabupaten Jepara terletak di pantai utara pulau Jawa, tepatnya di sebelah timur provinsi Jawa Tengah, di sebelah timur laut kota Semarang. Sementara itu, bagian barat dan utara dibatasi oleh laut. Sedangkan bagian timur wilayah kabupaten ini merupakan daerah pegunungan. Gunung yang terkenal adalah gunung Muria

Wilayah Kabupaten Jepara juga meliputi Kepulauan Karimunjawa, yakni gugusan pulau-pulau di Laut Jawa. Dua pulau terbesarnya adalah Pulau Karimunjawa dan Pulau Kemujan. Sebagian besar wilayah Karimunjawa dilindungi dalam Cagar Alam Laut Karimunjawa. Penyeberangan ke kepulauan ini dilayani oleh kapal feri yang bertolak dari Pelabuhan Jepara. Di Karimunjawa juga terdapat lapangan terbang perintis yang didarati pesawat berjenis kecil dari Semarang. Berikut ini adalah peta geografis wilayah Jepara. 


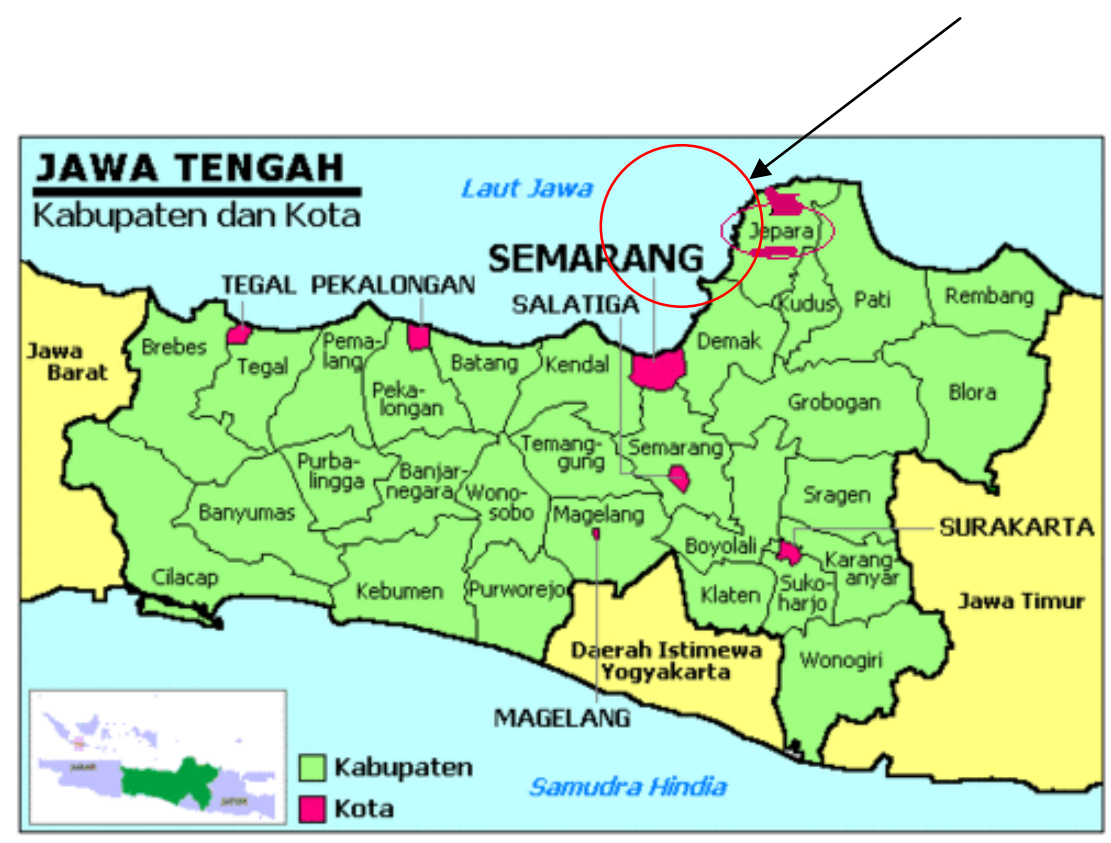

Gambar 1 Peta Geografis Wilayah Jepara

\section{Sejarah Jepara}

Jauh sebelum adanya kerajaan di tanah Jawa, di ujung utara pulau Jawa sudah ada warga yang percaya bahwa manusia berasal dari wilayah Yunnan Selatan yang kemudian bermigrasi ke selatan. Jepara masih dipisahkan oleh selat Juwana. Awalnya, nama Jepara berasal dari kata-kata Edge, Edge Mara dan Jumpara yang kemudian menjadi Jepara, yang berarti permukiman, tempat para pedagang menuju berbagai daerah. Sejarah Baru Dinasti Tang (618-906 M) mencatat bahwa pada tahun 674 Masehi, musafir China bernama I-Tsing pernah mengunjungi negeri Holing atau Kalinga (Kaling), atau juga dikenal sebagai Jawa atau Japa, dan diyakini berlokasi di Keling, Jepara timur hari ini. Kerajaan ini dipimpin oleh seorang wanita bernama Ratu Shima, raja yang dikenal sangat tegas.

Menurut seorang penulis Portugis, Tomé Pires, dalam Suma Oriental, Jepara baru dikenal yang pada abad XV (1470 M) sebagai pelabuhan perdagangan kecil yang baru dihuni oleh 90-100 orang dan dipimpin oleh Aryo Timur dan berada di bawah pemerintahan Demak. Kemudian, Aryo Timur digantikan oleh putranya bernama Pati Unus (1507-1521). Pati Unus mencoba untuk membangun sebuah kota Jepara. Pati Unus dikenal sangat gigih melawan Portugis di Malaka yang menguasai rantai perdagangan di kepulauan. Setelah Pati Unus meninggal, ia digantikan oleh ipar Faletehan, yakni Fatahillah, yang berkuasa pada 1521-1536. Kemudian tahun 1536 oleh sultan penguasa Demak, Trenggono, Jepara diserahkan kepada anak dan putri Ratu Retno Kencono dan Pangeran Ladies, suaminya. Akan tetapi, setelah kematian Sultan Trenggono dalam Ekspedisi Militer di Panarukan, Jawa Timur, pada 1546, insiden perebutan takhta kerajaan Demak amukan berakhir dengan kematian Pangeran Hadiri oleh Aryo Penangsang pada 1549. Kematian ini membuat Ratu Retno Kencono sangat berduka dan meninggalkan kehidupan istana untuk bertapa di bukit Danaraja. Setelah pembunuhan Aryo Penangsang oleh Sutowijoyo, Ratu Retno Kencono bersedia turun dari biara dan menjadi penguasa Jepara. Ia diresmikan oleh Ratu Kalinyamat, dengan gelar NIMAS. 




Gambar 2 Pemandangan kota Jepara di sekitar tahun 1650, dengan latar belakang Gunung Muria

(Sumber: wikipedia, 2013)

Selain bukti sejarah di atas, muncul pula sejarah yang berbentuk mitologi atau legenda. Diceritakan, dahulu kala hiduplah pengukir dan pelukis pada zaman Raja Brawijaya dari Kerajaan Majapahit, Jawa Timur. Pengukir itu bernama Prabangkara atau disebut juga dengan Joko Sungging. Raja Brawijaya ingin mempunyai lukisan istrinya dalam keadaan tanpa busana. Ini wujud rasa cinta sang raja. Dipanggillah ahli ukir dan lukis itu untuk mewujudkan keinginan Raja. Prabangkara mendapatkan tugas yang mustahil: melukis istri raja tanpa busana, tetapi tidak boleh melihat permaisuri dalam keadaan tanpa busana. Ia harus melukisnya melalui imajinasi saja. Prabangkara melaksanakan tugas tersebut, dan tugasnya selesai dengan sempurna. Tiba-tiba, seekor cecak mengeluarkan kotoran dan mengenai lukisan, sehingga lukisan permaisuri tersebut mempunyai tahi lalat. Raja gembira dengan hasil karya Prabangkara tersebut. Dilihatnya dengan detail gambar lukisan tersebut. Begitu dia melihat tahi lalat, raja murka. Dia menuduh Prabangkara melihat permaisuri tanpa busana karena lokasi tahi lalat persis dengan kenyataan. Raja cemburu dan menghukum Prabangkara dengan mengikatnya di layang-layang, kemudian menerbangkannya. Layang-layang itu terbang hingga ke Belakang Gunung di Jepara dan mendarat di Belakang Gunung itu. Belakang Gunung itu kini bernama Mulyoharjo di Jepara. Kemudian, Prabangkara mengajarkan ilmu ukir kepada warga Jepara. Kemahiran ukir warga Jepara bertahan dan lestari hingga sekarang.

\section{Sejarah Ukir Jepara}

Ukiran Jepara sudah ada jejaknya pada masa Pemerintahan Ratu Kalinyamat (1521-1546) pada 1549. Ratu mempunyai anak perempuan bernama Retno Kencono yang besar peranannya bagi perkembangan seni ukir. Di kerajaan, ada menteri bernama Sungging Badarduwung, yang datang dari Campa (Cambodia) dan dia adalah seorang pengukir yang baik. Ratu membangun Masjid Mantingan dan Makam Jirat (makam untuk suaminya), dan meminta Sungging untuk memperindah bangunan itu dengan ukiran. Sungging lalu memenuhi permintaan Ratu Kalinyamat. Hingga sekarang, ukiran itu bisa disaksikan di masjid dan Makam Sultan Hadlirin yang terdapat 114 relief pada batu putih.

Daerah Belakang Gunung konon terdapat kelompok ukir yang bertugas melayani kebutuhan ukir keluarga kerajaan. Kelompok ukir itu kemudian mengembangkan bakatnya dan tetangga sekitar ikut belajar dari mereka. Jumlah pengukir tambah banyak. Pada masa Ratu Kalinyamat kelompok mereka berkembang. Namun, sepeninggal Ratu Kalinyamat mereka stagnan. Dan kemudian berkembang lagi pada masa Kartini. 
Satu citra yang telah begitu melekat dengan Jepara adalah predikatnya sebagai "Kota Ukir". Ukir kayu telah menjadi idiom kota kelahiran Raden Ajeng Kartini ini, dan bahkan belum ada kota lain yang layak disebut sepadan dengan Jepara untuk industri kerajinan mebel ukir. Akan tetapi, untuk sampai pada kondisi seperti ini, Jepara telah menapak perjalanan yang sangat panjang. Sejak jaman kejayaan Negara-negara Hindu di Jawa Tengah, Jepara telah dikenal sebagai pelabuhan utara pantai Jawa yang juga berfungsi pintu gerbang komunikasi antara kerajaan Jawa dengan Cina dan India.

Demikian juga pada saat kerajan Islam pertama di Demak, Jepara telah dijadikan sebagai pelabuhan Utara selain sebagai pusat perdagangan dan pangkalan armada perang. Pada masa penyebaran agama Islam oleh para Wali, Jepara juga dijadikan daerah "pengabdian” Sunan Kalijaga yang mengembangkan berbagai macam seni, termasuk seni ukir.

Faktor lain yang melatarbelakangi perkembangan ukir kayu di Jepara adalah para pendatang dari negeri Cina yang kemudian menetap. Dalam catatan sejarah perkembangan ukir kayu, tak dapat dilepaskan pula dari peranan Ratu Kalinyamat. Pada masa pemerintahannya ia memiliki seorang patih yang bernama "Sungging Badarduwung” yang berasal dari Negeri Campa. Patih ini ternyata seorang ahli pahat yang dengan sukarela mengajarkan keterampilannya kepada masyarakat di sekitarnya. Satu bukti yang masih dapat dilihat dari seni ukir masa pemerintahan Ratu Kalinyamat ini adalah adanya ornamen ukir batu di Masjid Mantingan.

Di samping itu, peranan Raden Ajeng Kartini dalam pengembangkan seni ukir juga sangat besar. Raden Ajeng Kartini yang melihat kehidupan para pengerajin tak juga beranjak dari kemiskinan, batinnya terusik, sehingga ia bertekat mengangkat derajat para pengerajin. Ia memanggil beberapa pengerajin dari Belakang Gunung (kini salah satu padukuhan Desa mulyoharjo) di bawah pimpinan Singowiryo, untuk bersama-sama membuat ukiran di belakang Kabupaten. Oleh Raden Ajeng Kartini, mereka diminta untuk membuat berbagai macam jenis ukiran, seperti peti jahitan, meja keci, figura, tempat rokok, tempat perhiasan, dan barang souvenir lainnya. Barang-barang ini kemudian dijual Raden Ajeng Kartini ke Semarang dan Batavia (sekarang Jakarta), sehingga akhirnya diketahui bahwa masyarakat Jepara pandai mengukir.

Setelah banyak pesanan yang datang, hasil produksi para pengerajin Jepara bertambah jenis, seperti: kursi pengantin, alat panahan angin, tempat tidur pengantin dan penyekat ruangan serta berbagai jenis kursi tamu dan kursi makan. Raden Ajeng Kartini juga mulai memperkenalkan seni ukir Jepara keluar negeri. Caranya, Raden Ajeng Kartini memberikan souvenir kepada sahabatnya di luar negeri. Akibatnya, seni ukir terus berkembang dan pesanan terus berdatangan. Seluruh penjualan barang, setelah dikurangi dengan biaya produksi dan ongkos kirim, uangnya diserahkan secara utuh kepada para pengerajin.

Untuk menunjang perkembangan seni ukir Jepara yang telah dirintis oleh Raden Ajeng Kartini, pada 1929 timbul gagasan dari beberapa orang pribumi untuk mendirikan sekolah kejuruan. Tepat pada tanggal 1 Juli 1929, sekolah pertukangan dengan jurusan mebel dan ukir dibuka dengan nama “Openbare Ambachtsschool” yang kemudian berkembang menjadi Sekolah Teknik Negeri dan Kemudian menjadi Sekolah Menengah Industri Kerajinan Negeri. 




Gambar 3 Repro negatif potret Raden Ajeng Kartini (foto 1890-an)

(Sumber: Wikipedia, 2013)

Dengan adanya sekolah kejuruan ini, kerajinan mebel dan ukiran meluas di kalangan masyarakat. Makin banyak pula anak yang masuk sekolah ini agar mendapatkan kecakapan pada bidang mebel dan ukir. Di sekolah ini diajarkan berbagai macam desain motif ukir serta ragam hias Indonesia yang pada mulanya belum diketahui oleh masyarakat Jepara. Tokoh-tokoh yang berjasa dalam pengembangan motif lewat lembaga pendidikan ini adalah Raden Ngabehi Projo Sukemi, yang mengembangkan motif Majapahit dan Pajajaran, serta Raden Ngabehi Wignjopangukir, yang mengembangkan motif Pajajaran dan Bali.

Semakin bertambahnya motif ukir yang dikuasai oleh para pengerajin Jepara, mebel dan ukiran Jepara semakin diminati. Para pedagang pun mulai memanfaatkan kesempatan ini untuk mendapatkan barang-barang baru guna memenuhi permintaan konsumen, baik yang berada di dalam maupun di luar negeri. Alur sejarah ukiran kota Jepara terangkum dalam gambar berikut.

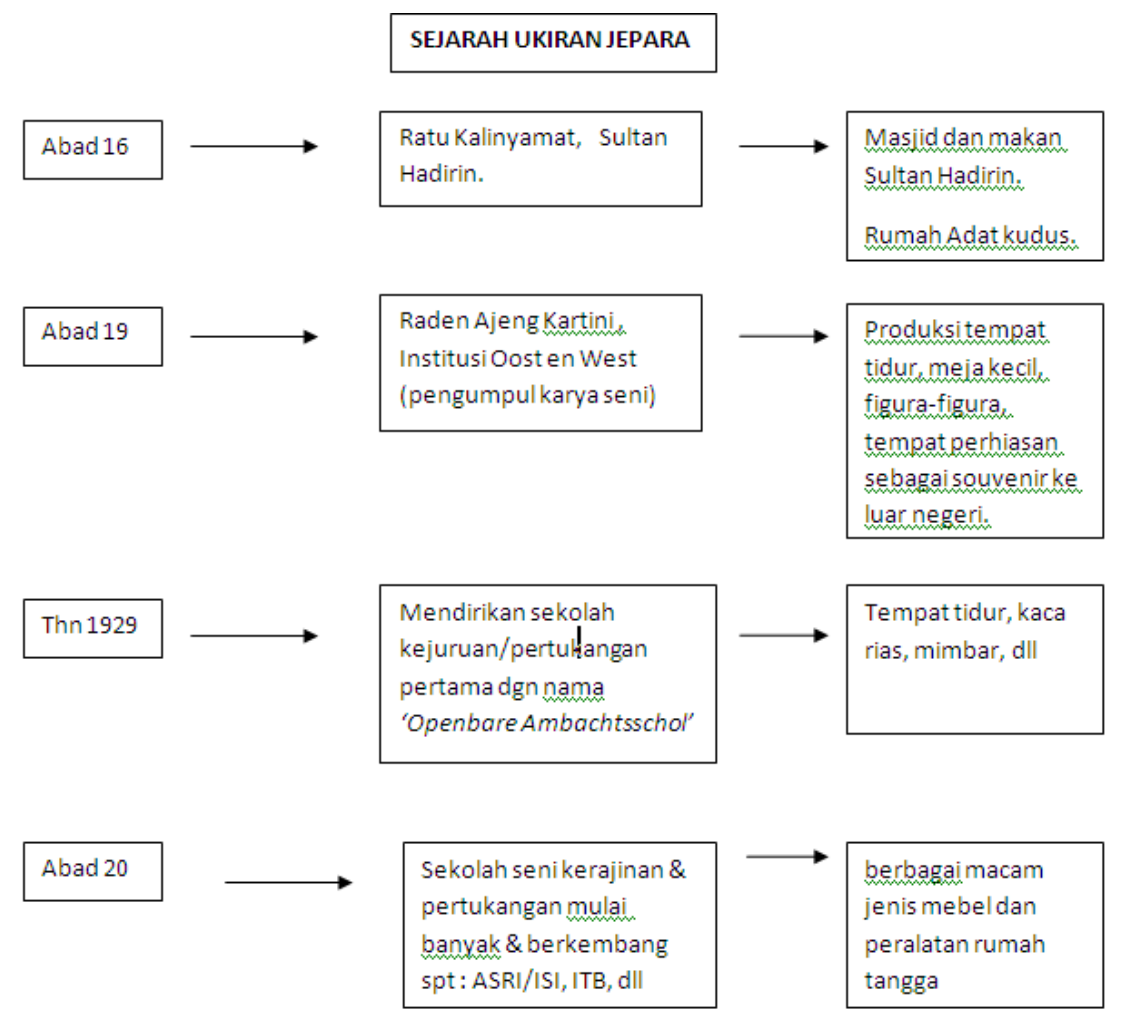

Gambar 4 Alur Sejarah Ukiran Kota Jakarta 


\section{SIMPULAN}

Setelah mengalami perubahan dari kerajinan tangan menjadi industri kerajinan, terutama bila dipandang dari segi sosial ekonomi, ukiran kayu Jepara terus melaju pesat. Hal ini membuat Jepara mendapatkan predikat sebagai kota ukir. Di tengah keberhasilannya menguasai pasar mebel nasional, ukiran Jepara mencoba melakukan ekspansi ke pasar internasional dengan melakukan inovasi-inovasi dalam desain dan teknologi pertukangan agar dapat memenuhi selera pasar.

Langkah-langkah yang ditempuh untuk meningkatkan kualitas mebel ukir Jepara adalah menejemen produksi dan menejemen pemasaran. Di samping itu, dikembangkan "Semangat Jepara Incoporated“, bersatunya pengusaha Jepara dalam memasuki pasar ekspor, yang menuntut persiapan matang karena persaingan yang begitu ketat .

Guna meningkatkan kualitas Sumber Daya Manusia misalnya, dilakukan melalui pendidikan Sekolah Menengah Industri Kerajinan Negeri dan Akademi Teknologi Perkayuan dan pendidikan non formal melalui kursus-kursus dan latihan-latihan. Dengan peningkatan kualitas sumber daya manusia ini, diharapkan bukan saja dapat memacu kualitas produk, tetapi juga memacu kemampuan para pengerajin dan pengusaha Jepara dalam pembaca peluang pasar dengan segala tentutannya.

Peningkatan kualitas produk dan pengawasan mutu memang menjadi obsesi Jepara dalam memasuki pasar internasional, yang bertujuan untuk meningkatkan kepercayaan luar negeri terhadap produk industri Jepara. Karena itu, pengendalian mutu dengan mengacu pada sistem standar internasional merupakan hal yang tidak dapat ditawar-tawar lagi. Usaha ini dilakukan melalui pembinaan terhadap produsen agar mempertahankan mutu produknya dalam rangka menjamin mutu pelayanan yang merupakan persyaratan ISO 9000.

Di samping itu, perluasan dan intensifikasi pasar terus dilakukan dalam rangka meningkatkan ekspor serta peluasan pasar internasional dengan penganeragaman produk yang mempunyai potensi, serta peningkatan market intelligence untuk memperoleh transportasi pasar luar negeri. Dengan demikian, para pengusaha dapat dengan tepat dan cepat mengantisipasi peluang serta tantangan yang ada di pasar internasional. Sementara itu, jaringan informasi terus dilakukan melalu pengefektivan fungsi dan kegiatan Buyer Reception Desk yang ada di Jepara. Langkah-langkah konseptual yang dilakukan secara terus menerus ini telah membuahkan keberhasilan yang dampaknya dirasakan oleh masyarakat Jepara, berupa peningkatan kesejateraannya.

\section{DAFTAR PUSTAKA}

Gustami, S. P. (2000). Seni Kerajinan Ukir Jepara. Yogyakarta: Penerbit Kanisius.

Munoz, P. M. (2006). Early Kingdoms of the Indonesian Archipelago and the Malay Peninsula. Singapore: Editions Didier Millet.

Soekmono, R. (1988). Pengantar Sejarah Kebudayaan Indonesia 2, 2nd ed. Yogyakarta: Penerbit Kanisius.

Tim IPS. IPS Terpadu Kelas VII SMP/MTs. Jakarta: Galaxy Puspa Mega.

wikipedia. (2013, February 13). id.wikipedia.org. Retrieved February 20, 2013, from wiki/Kabupaten_Jepara\#Sejarah: http://id.wikipedia.org/wiki/Kabupaten_Jepara\#Sejarah. 
http://pushtop.blogspot.com/2011/04/asal-usul-seni-ukir-jepara-legenda-ki.html.

http://regional.kompas.com/read/2012/07/13/06201271/Kerajinan.Ukir.Jepara.Maju Sekaligus.Mundur. 